Article

\title{
Environmentally Benign Organic Dye Conversion under UV Light through $\mathrm{TiO}_{2}-\mathrm{ZnO}$ Nanocomposite
}

\author{
Sandip M. Deshmukh ${ }^{1}$, Sudhir S. Arbuj ${ }^{2}$, Santosh B. Babar ${ }^{1}{ }^{1}$, Shoyebmohamad F. Shaikh ${ }^{3}$, \\ Asiya M. Tamboli ${ }^{4, *}$, Nguyen Tam Nguyen Truong ${ }^{4}$, Chang-Duk Kim ${ }^{5}$, Sanjay M. Khetre ${ }^{6, *}$, \\ Mohaseen S. Tamboli ${ }^{4, * \mathbb{C}}$ and Sambhaji R. Bamane ${ }^{7}$
}

Citation: Deshmukh, S.M.; Arbuj, S.S.; Babar, S.B.; Shaikh, S.F.; Tamboli, A.M.; Nguyen Truong, N.T.; Kim, C.-D.; Khetre, S.M.; Tamboli, M.S.; Bamane, S.R. Environmentally Benign Organic Dye Conversion under UV Light through $\mathrm{TiO}_{2}-\mathrm{ZnO}$ Nanocomposite. Metals 2021, 11, 1787. https://doi.org/10.3390/ met11111787

Academic Editor:

Houshang Alamdari

Received: 5 October 2021

Accepted: 2 November 2021

Published: 6 November 2021

Publisher's Note: MDPI stays neutral with regard to jurisdictional claims in published maps and institutional affiliations.

Copyright: (c) 2021 by the authors. Licensee MDPI, Basel, Switzerland. This article is an open access article distributed under the terms and conditions of the Creative Commons Attribution (CC BY) license (https:// creativecommons.org/licenses/by/ $4.0 /)$.
1 Department of Chemistry, VNBN Mahavidyalaya, Shirala 415408, Maharashtra, India; sandip.deshmukh555@gmail.com (S.M.D.); santosh87babar@gmail.com (S.B.B.)

2 Centre for Materials for Electronics Technology, Materials of Renewable Energy and Sensor Division, Panchawati Off Pahsan Road, Pune 411008, Maharashtra, India; sudhir1305@gmail.com

3 Department of Chemistry, College of Science, King Saud University, Riyadh 11451, Saudi Arabia; shoyeb.chemist@gmail.com

4 School of Chemical Engineering, Yeungnam University, 280 Daehak-ro, Gyeongsan 38541, Korea; tamnguyentn@ynu.ac.kr

5 Department of Physics, Kyungpook National University, 80 Daehakro, Bukgu, Daegu 41566, Korea; duks@knu.ac.kr

6 Nanomaterials Research Laboratory, Department of Chemistry, Dahiwadi College, Dahiwadi 415508, Maharashtra, India

7 Department of Chemistry, Sushila Shankarrao Gadhave Mahavidyalaya, Khandala 412802, Maharashtra, India; sambhajibamane@yahoo.com

* Correspondence: asiyashaikh2020@gmail.com (A.M.T.); sanjaykhetre@gmail.com (S.M.K.); tamboli.mohseen@gmail.com (M.S.T.)

Abstract: In this work, we developed a very simple and novel approach for synthesizing $\mathrm{TiO}_{2}$ $\mathrm{ZnO}$ nanocomposites via the urea-assisted thermal decomposition of titanium oxysulphate and zinc acetate at different weight ratios. The synthesized nanocomposite samples were studied by means of HR-TEM, XRD, STEM, UV-Vis DRS, PL and EDS. The observed results demonstrate that the $\mathrm{TiO}_{2}-\mathrm{ZnO}$ nanocomposite consists of an anatase crystal phase of $\mathrm{TiO}_{2}$ with a crystallite size of 10-15 nm. Combined characterization, including UV-Vis DRS, STEM, EDS and HR-TEM, revealed the successful formation of a heterojunction between $\mathrm{TiO}_{2}$ and $\mathrm{ZnO}$ and an improvement in UV spectrum absorption. The photocatalytic activity was explored using MO degradation under ultraviolet light illumination. The results of the optimized $\mathrm{TiO}_{2}-\mathrm{ZnO}$ nanocomposite show excellent photocatalytic activity and photostability over a number of degradation reaction cycles. In addition, the current approach has immense potential to be used as a proficient method for synthesizing mixed metal oxide nanocomposites.

Keywords: $\mathrm{TiO}_{2}-\mathrm{ZnO}$; urea; nanocomposite; combustion; photocatalysis

\section{Introduction}

The major pollutants released into the ecosystem due to increased population and industrialization have turned out to be an environmental concern. These pollutants have been converted into nontoxic as well as less toxic substances using various physical, chemical and biological techniques. Recently, advanced oxidative methods such as semiconductor metal oxide-based photocatalysis have received enormous attention for their effective degradation of pollutants present in air, water and soil. This technique is low cost, is environmentally friendly, can function at ambient reaction conditions and is useful for a wide range of pollutants [1-3].

Numerous metal oxides such as $\mathrm{ZnO}, \mathrm{TiO}_{2}, \mathrm{Fe}_{2} \mathrm{O}_{3}, \mathrm{Ta}_{2} \mathrm{O}_{5}$ and $\mathrm{Bi}_{2} \mathrm{O}_{3}$ have been used as photocatalysts for the degradation of various aqueous dye pollutants [4-8]. Among 
the various metal oxides, $\mathrm{TiO}_{2}$ has been used as a photocatalytic material with great potential due to its excellent photocatalytic activity, wide energy band gap $(3.2 \mathrm{eV})$, nontoxic nature, chemical stability and cost effectiveness [9]. However, the main problem with $\mathrm{TiO}_{2}$ is its wide band gap of $3.2 \mathrm{eV}$, which requires $\mathrm{UV}$ light for performing photocatalytic reactions [10].

To date, different approaches have been tested in order to improve the photocatalytic activity of $\mathrm{TiO}_{2}$ such as cation and anion doping to alter the band gap, loading of noble metal nanoparticles and coupling with other semiconductor-based metal oxides/sulfides for the effective separation of photogenerated charge carriers [11-13]. The coupling of $\mathrm{TiO}_{2}$ with different metal oxides such as $\mathrm{CuO}, \mathrm{NiO}, \mathrm{Ta}_{2} \mathrm{O}_{5}, \mathrm{Nb}_{2} \mathrm{O}_{5}$ and $\mathrm{ZnO}$ shows a great enhancement in photocatalytic activity due to the increase in the lifetime of photogenerated charge carriers, the effective electron-hole pair separation and the modification of optical properties [14-18].

Among the various studied metal oxides, the coupling of $\mathrm{ZnO}$ with $\mathrm{TiO}_{2}$ creates one of the most efficient photocatalysts because of the development of heterojunction structures. Notably, $\mathrm{ZnO}$ possesses a wide band gap of $3.37 \mathrm{eV}$, high electron mobility, large exciton binding energy $(60 \mathrm{meV})$ and similar band gap energies to $\mathrm{TiO}_{2}$ [19]. It is suggested that the formation of the type II heterojunction in the $\mathrm{TiO}_{2}-\mathrm{ZnO}$ composite might possibly facilitate the transfer of electrons from the conduction band $(\mathrm{CB})$ of $\mathrm{TiO}_{2}$ to the $\mathrm{CB}$ of $\mathrm{ZnO}$ under $\mathrm{UV}$ light irradiation. Consequently, the electron-hole recombination rate is suppressed and photocatalytic activity is enhanced [20]. Further, the $\mathrm{TiO}_{2}-\mathrm{ZnO}$ nanocomposite's activity can be enhanced by changing the synthesis method.

More recently, some methods have been developed for the fabrication of $\mathrm{TiO}_{2}-\mathrm{ZnO}$ nanocomposites including sol-gel, hydrothermal, atomic layer deposition and microwave methods [21-24]. Despite these advanced methods, these strategies possess some drawbacks such as the fact that they are time consuming and costly and involve hazardous substrates and complicated reaction procedures. In this regard, we have developed a thermal decomposition approach for the large-scale synthesis of the nanostructured $\mathrm{TiO}_{2}-\mathrm{ZnO}$ heterostructure as a rapid, easy, low-cost and eco-friendly technique. $\mathrm{TiO}_{2}-\mathrm{ZnO}$ nanoheterostructures were prepared by varying the $\mathrm{ZnO}$ concentration, and we studied their photocatalytic performance towards the degradation of aqueous methylene blue dye. To the best of our knowledge, this thermal decomposition approach for the one-step synthesis of $\mathrm{TiO}_{2}-\mathrm{ZnO}$ nano-heterostructures is the first attempt of its kind and could be the easiest possible method.

\section{Experimental Section}

2.1. Materials

Titanium oxysulphate $\left(\mathrm{TiOSO}_{4} \cdot \mathrm{H}_{2} \mathrm{O}\right)$ zinc acetate $\left(\mathrm{Zn}\left(\mathrm{CH}_{3} \mathrm{CO}_{2}\right)_{2} \cdot 2 \mathrm{H}_{2} \mathrm{O}\right)$ and urea $\left(\mathrm{CON}_{2} \mathrm{H}_{4}\right)$ were purchased from Sigma-Aldrich (Bangalore, India). Methyl orange purchased from Molychem (Mumbai, India) was of analytical grade and was used as received, without further purification.

\subsection{Preparation of $\mathrm{TiO}_{2}, \mathrm{ZnO}$ and $\mathrm{TiO}_{2}-\mathrm{ZnO}$ Composite}

$\mathrm{TiO}_{2}$ and $\mathrm{ZnO}$ nanostructures were separately prepared using a urea-assisted thermal decomposition method in a similar manner to our previous report [25]. In the typical synthesis of the $\mathrm{TiO}_{2}-\mathrm{ZnO}$ nanocomposite, grinding of titanium oxysulphate, zinc acetate and urea was carried out for $15 \mathrm{~min}$ using a mortar and pestle. The obtained powder was heated at $600{ }^{\circ} \mathrm{C}$ in a muffle furnace with a heating rate of $15^{\circ} \mathrm{C}$ per minute for $3 \mathrm{~h}$. Then, the final product was washed with distilled water (DW) and dried in the oven at $80^{\circ} \mathrm{C}$. The obtained products were finally ground into a fine powder in a mortar and pestle. $\mathrm{TiO}_{2}$ and $\mathrm{ZnO}$ were also synthesized with the addition of urea and denoted as $\mathrm{TU}$ and $\mathrm{ZU}$, respectively. The precursors (titanium oxysulphate and zinc acetate) had weight ratios of 0.95:0.05, 0.90:0.10, 0.85:0.15, 0.80:0.20, 0.75:0.25 and 0.70:0.30 and were denoted as TZU95, 
TZU90, TZU85, TZU80, TZU75 and TZU70, respectively. The as-prepared products were used for further characterization.

\subsection{Characterization}

The crystalline structures of the as-prepared $\mathrm{TiO}_{2}$ and $\mathrm{ZnO}$ nanomaterials and $\mathrm{TiO}_{2}-$ $\mathrm{ZnO}$ nanocomposites were identified by the $\mathrm{X}$-ray diffraction technique (Pan analytical diffractometer, Almelo, The Netherlands) using $\mathrm{CuK} \alpha$ radiation $(\lambda=1.5406 \AA)$, which provides detection limits in the range of 0.1 to $1 \mathrm{wt} . \%$ per phase. With the help of field-emission scanning electron microscopy (FE-SEM, Hitachi S-4800 with an accelerating voltage range of $10.0 \mathrm{kV}$ ), field-emission transmission electron microscopy (Titan G2 ChemiSTEM Cs Probe, FEI Company, Hillsboro, OR, USA) the morphological features of the samples were investigated. The chemical composition and element allocation in a selected area were analyzed by scanning transmission electron microscopy elemental mapping using an $\mathrm{X}$-ray energy-dispersive spectrometer (Titan G2 ChemiSTEM Cs Probe, FEI Company, Hillsboro, OR, USA). The absorption profile and band gap of the composites were studied using a UV-Vis spectrophotometer (Shimadzu, Model-UV-3600, Kyoto, Japan), and photoluminescence spectra (PL) were analyzed using a spectrofluorophotometer (JASCO, Model FP.750, Tokyo, Japan).

\subsection{Evaluation of Photocatalytic Performance}

The photocatalytic activities of TU, ZU, TZU95, TZU90, TZU85, TZU80, TZU75 and TZU70 were evaluated by observing the degradation of methyl orange (MO), as an organic dye, at room temperature. For this purpose, $0.1 \mathrm{~g}$ of the photocatalyst was dispersed in 100 $\mathrm{mL}$ of aqueous solution with $20 \mathrm{ppm}$ of MO dye. A Philips HPL-N (Amsterdam, Netherlands, $250 \mathrm{~W}$, wavelength range of 200-600 nm) lamp was utilized as a UV-visible light source, at room temperature. Before the irradiation, the reaction mixture was stirred (on a magnetic stirrer) in the dark for half an hour, in order to achieve adsorption-desorption equilibrium between the methyl orange molecules and catalyst samples.

At definite time intervals, $3 \mathrm{~mL}$ of solution was removed, and the catalyst was separated by centrifugation. The concentration of the dye solution was quantitatively calculated by monitoring the absorbance of $\mathrm{MO}$ at $464 \mathrm{~nm}$ through the UV-Vis spectrophotometer (Shimadzu, Model-UV-3600, Kyoto, Japan). The recyclability study was also carried out using the used catalyst by maintaining the same reaction conditions.

\section{Results and Discussion}

\subsection{XRD Analysis}

The crystalline structures of as-prepared materials were studied using XRD analysis. Figure 1 exhibits the XRD pattern of TU, ZU, TZU95, TZU90, TZU85, TZU80, TZU75 and TZU70. As shown in Figure 1, the characteristic peaks of TU, observed at $2 \theta=25.3^{\circ}$, $37.8^{\circ}, 48.0^{\circ}, 53.9^{\circ}, 55.1^{\circ}, 62.7^{\circ}, 68.9^{\circ}, 70.3^{\circ}$ and $75.1^{\circ}$, correspond to the reflection planes of (101), (004), (200), (105), (211), (204), (116), (220) and (215), respectively, which indicates the formation of $\mathrm{TiO}_{2}$ in the anatase phase and clearly matches with the reported pattern (JCPDS 21-1272) [25]. For the ZU sample shown in Figure 1, the characteristic peaks of $\mathrm{ZnO}$ appear at $31.63^{\circ}, 34.29^{\circ}, 36.32^{\circ}, 47.54^{\circ}, 56.72^{\circ}, 62.83^{\circ}$ and $67.93^{\circ}$ and can be indexed to the planes of (100), (002), (101), (102), (110), (103) and (112), which indicates the existence of the hexagonal wurtzite structure of ZnO (JCPDS 36-1451) [26]. For the TZU95 and TZU90 nanocomposite samples, no characteristic diffraction peaks of $\mathrm{ZnO}$ are found; this may be because the lower weight ratio of the $\mathrm{ZnO}$ precursor is below the detection limit of XRD. On the other hand, the TZU85, TZU80 and TZU75 nanocomposite samples show the slight appearance of the characteristic peaks of wurtzite $\mathrm{ZnO}$, ranging from $30^{\circ}$ to $38^{\circ}$, which correspond to the reflection planes of (100), (002) and (101). XRD confirmed that the thermal decomposition of titanium oxysulphate, zinc acetate and urea is a very proficient method for the successful formation of the $\mathrm{TiO}_{2}-\mathrm{ZnO}$ nanocomposite. In addition, no impurity peaks are observed in the TZU95, TZU90, TZU85, TZU80 and TZU75 samples, indicating 
that the coupling of the $\mathrm{TiO}_{2}$ anatase phase and the $\mathrm{ZnO}$ hexagonal wurtzite forms the $\mathrm{TiO}_{2}-\mathrm{ZnO}$ nanocomposite. Furthermore, coupling of $\mathrm{ZnO}$ with $\mathrm{TiO}_{2}$ in the TZU95, TZU90, TZU85, TZU80 and TZU75 samples still maintains the anatase phase of $\mathrm{TiO}_{2}$. However, it should be noted that the TZU70 sample shows weak peaks at $28.8^{\circ}$, suggesting the formation of a new $\mathrm{Zn}_{2} \mathrm{TiO}_{4}$ phase [27].

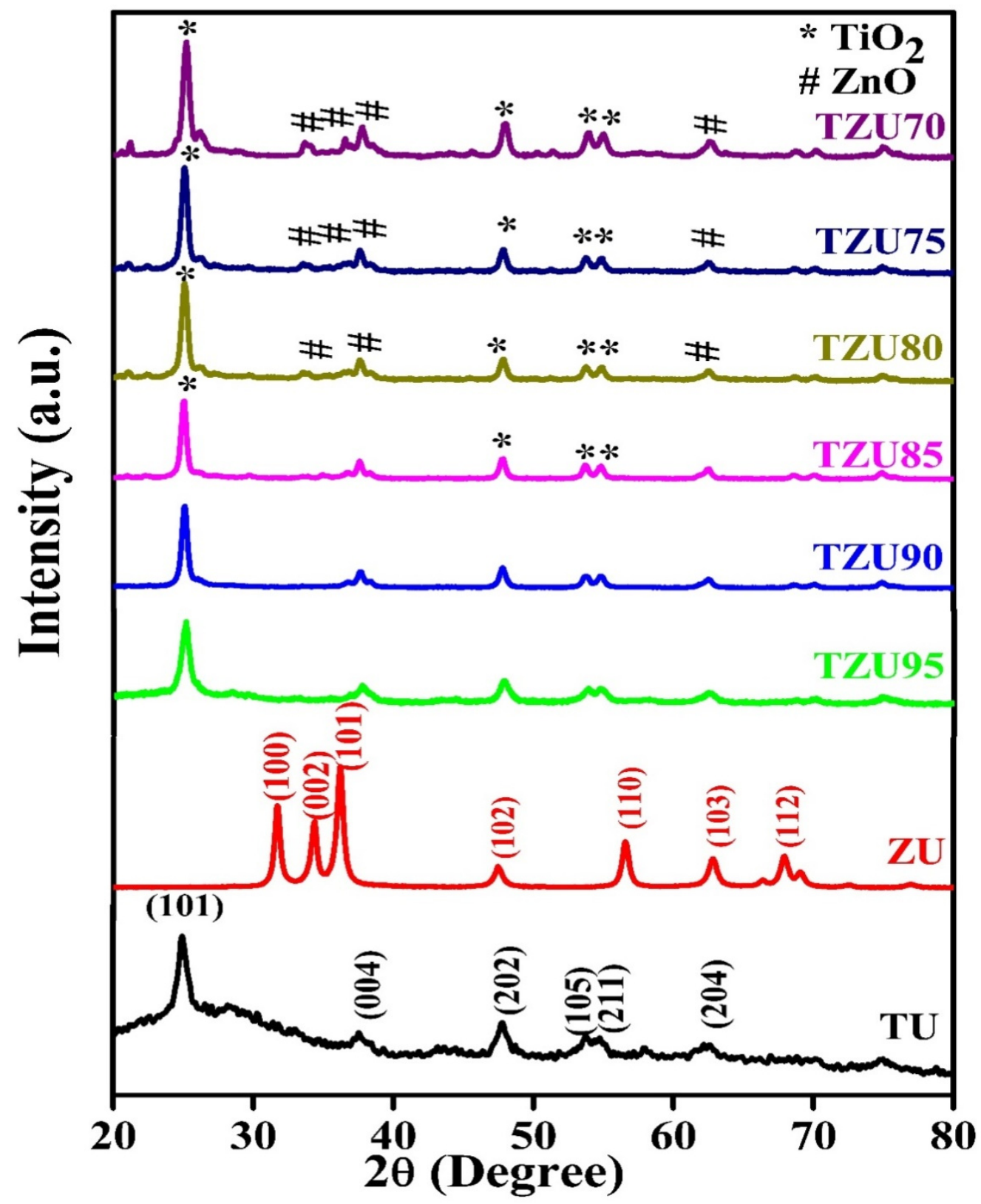

Figure 1. XRD patterns of TU, ZU, TZU95, TZU90, TZU85, TZU80, TZU75 and TZU70.

The crystallite sizes (D) of the TU, ZU, TZU95, TZU90, TZU85, TZU80, TZU75 and TZU70 samples were calculated using Scherrer's equation [28].

$$
\mathrm{D}=\frac{0.9 \lambda}{\beta \cos \theta}
$$

where ' $\lambda$ ' indicates the wavelength of the X-ray employed, ' $\theta$ ' stands for the angle of diffraction for a more intense diffraction peak and ' $\beta$ ' stands for the full width at half maximum of the most intense diffraction peak (FWHM). The diffraction peak (101) was 
used to calculate the crystallite sizes of the samples. The crystallite sizes of the TU, ZU, TZU95, TZU90, TZU85, TZU80, TZU75 and TZU70 samples are about 14, 13.9, 12.8, 15.2, $14.8,15.3,13.3$ and $15 \mathrm{~nm}$, respectively.

\subsection{Structure and Morphological Analysis}

The morphology and structure of the $\mathrm{TiO}_{2}-\mathrm{ZnO}$ nanocomposite were studied using SEM, EDX, HRTEM and STEM. Figure 2a-d portray the SEM images of the TZU75 nanocomposite with various magnifications. It can be clearly seen that the TZU75 nanocomposite is composed of porous and aggregated nanoparticles (NPs) of $\mathrm{TiO}_{2}$ and $\mathrm{ZnO}$. In addition, spherical-shaped NPs are interconnected which may lead to interfacial interaction and to the formation of a heterojunction between $\mathrm{TiO}_{2}$ and $\mathrm{ZnO}$ NPs.

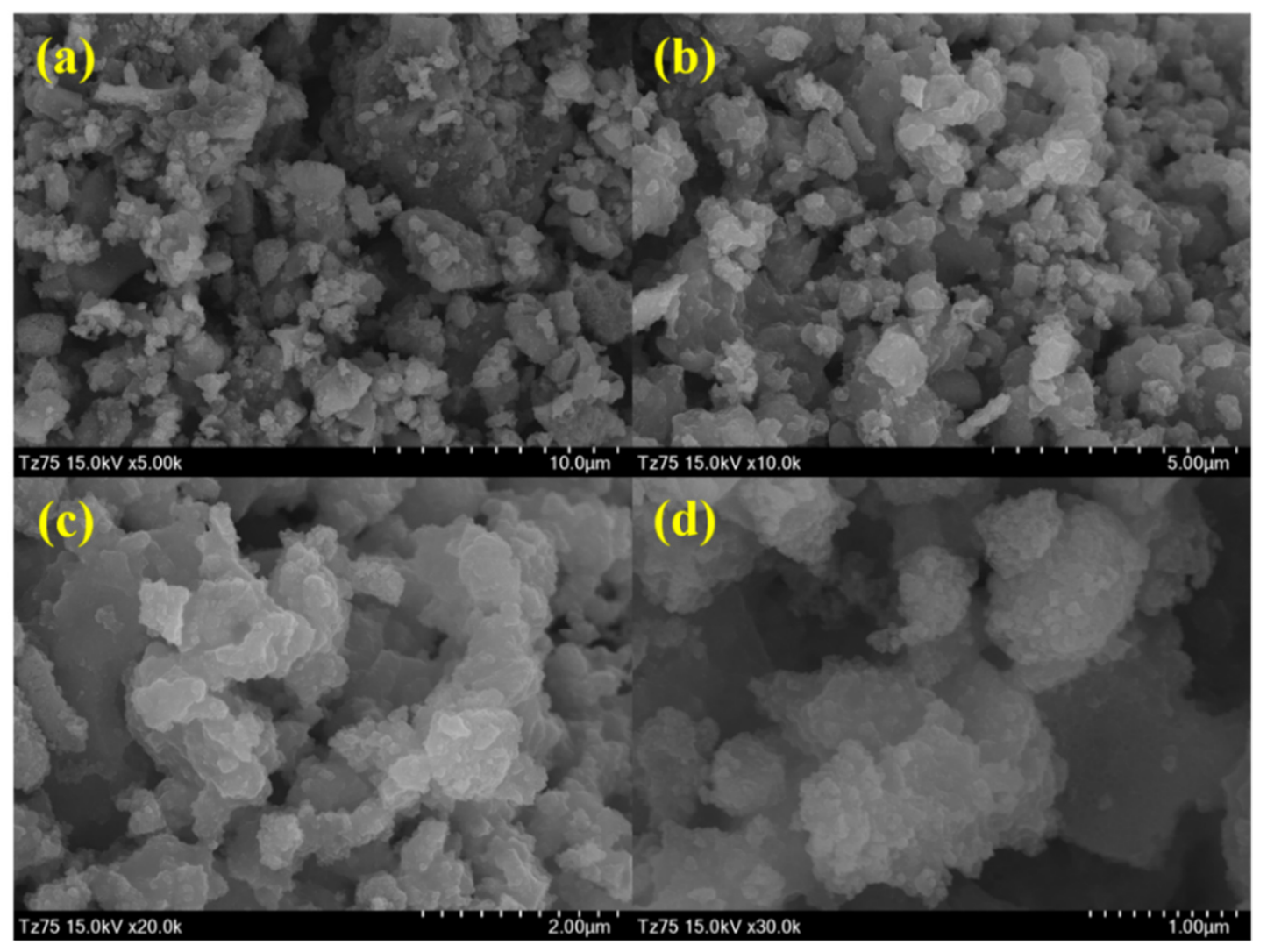

Figure 2. SEM images of (a-d) TZU75 nanocomposite.

Figures 2a-d and 3a-d show the SEM and TEM images of TZU75, which reveal no distinct boundary between the $\mathrm{TiO}_{2}$ and $\mathrm{ZnO}$ phases; this might be because of the similar structure and morphology of the $\mathrm{TiO}_{2}$ and $\mathrm{ZnO}$ NPs. For further proof of the existence of the nanocomposite, TEM was used to examine the morphology of the samples. Figure $3 a-d$ show that $\mathrm{TiO}_{2} \mathrm{NPs}$ with $\mathrm{ZnO}$ are found in the form of interconnected, aggregated, spherical, slightly hierarchical and porous NPs with a higher surface area. The size of the NPs is well within the range of 10 to $30 \mathrm{~nm}$ and, notably, matches with the XRD results. HR-TEM, STEM and elemental mapping of the TZU75 nanocomposite were carried out to check the presence of $\mathrm{Zn}$ and Ti. Lattice fringes of 0.356 and $0.262 \mathrm{~nm}$, measured in the HRTEM image of the TZU75 sample, correspond to the interplanar distances of the (101) and (002) crystallographic planes of $\mathrm{TiO}_{2}$ and $\mathrm{ZnO}$, respectively [29]. Furthermore, the elemental mapping (Figure $3 \mathrm{e}-\mathrm{h}$ ) demonstrated the uniform distribution of $\mathrm{Ti}, \mathrm{O}$ and $\mathrm{Zn}$ atoms throughout the nanocomposite. Interestingly, the elemental mapping showed that the $\mathrm{ZnO}$ NPs consistently spread over the entire surface of the $\mathrm{TiO}_{2}$ nanostructure, signifying the formation of the nano-heterostructure. 


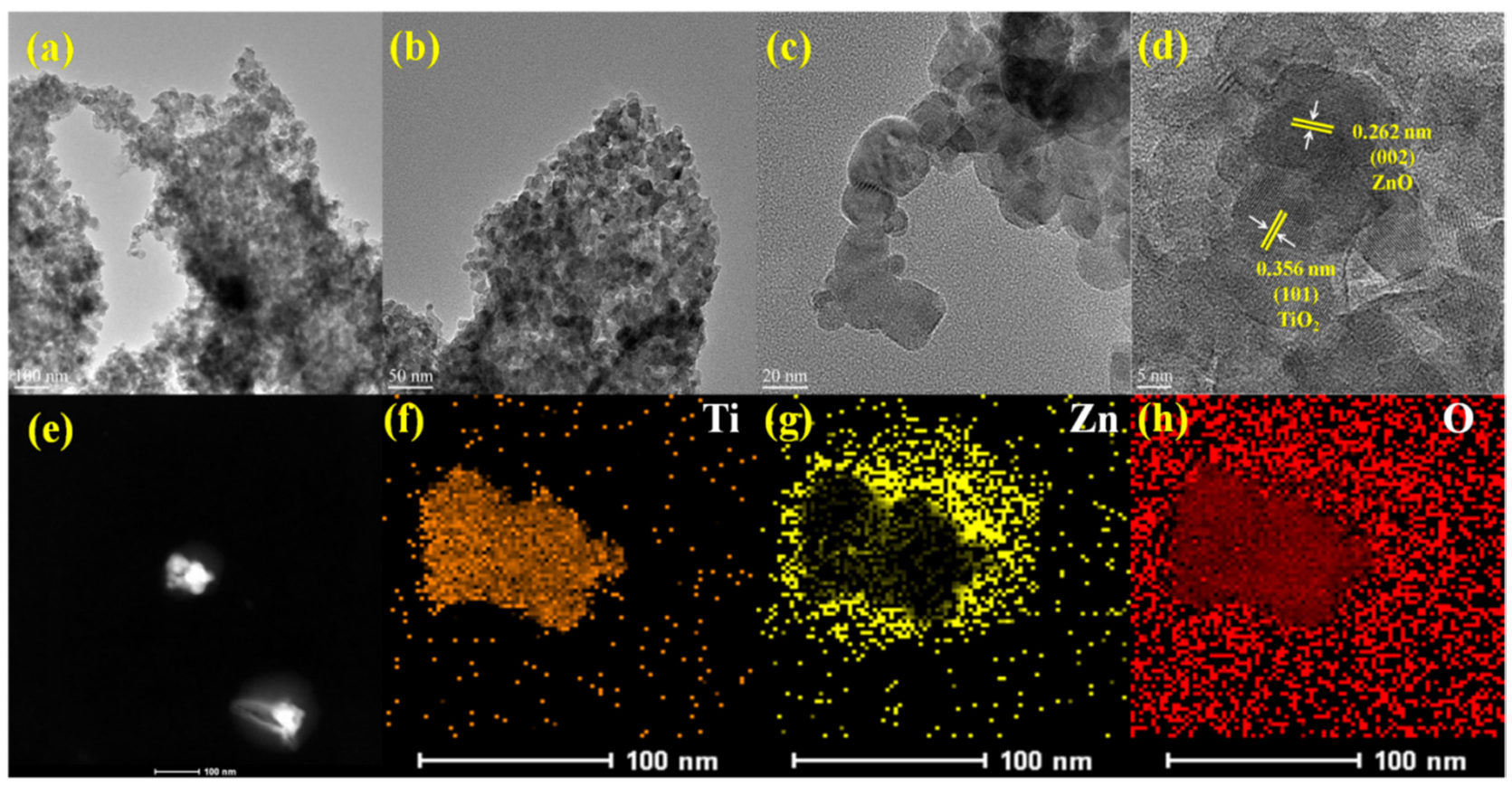

Figure 3. (a,b) TEM, (c,d) HRTEM and (e) STEM images and the corresponding (f-h) elemental mapping of the TZU75 nanocomposite.

\subsection{Optical Properties}

The activity of the photocatalyst is highly dependent on the absorption of light together with its quantity and wavelength. To investigate the optical properties, we used UV-Vis diffuse reflectance spectra for the TU, ZU, TZU95, TZU90, TZU85, TZU80, TZU75 and TZU70 samples. As shown in Figure 4, TU and ZU exhibit pronounced absorption in the UV region. Remarkably, the addition of $\mathrm{ZnO}$ to $\mathrm{TiO}_{2}$, the TZU75 nanocomposite exhibited increased absorption in both the UV and visible regions, which is ascribed to the transfer of electrons from the valence band (VB) to the conduction band (CB) [30]. The successful formation of $\mathrm{TiO}_{2}-\mathrm{ZnO}$ heterojunctions reduces the recombination rate of the photoinduced electron-hole pair and enhances the photocatalytic activity of the $\mathrm{TiO}_{2}-\mathrm{ZnO}$ nanocomposite.

\subsection{PL Spectra}

Photoluminescence (PL) spectra were implemented to study the recombination rate of the photoinduced electron-hole pair and the scope of charge separation. The photoluminescence spectra of the photocatalysts had an excitation wavelength of $295 \mathrm{~nm}$ for $\mathrm{TiO}_{2}$ and the $\mathrm{TiO}_{2}-\mathrm{ZnO}$ nanocomposite, at room temperature, as depicted in Figure 5. The PL spectra depict two broad emission peaks centered at 410 and $470 \mathrm{~nm}$, which correspond to the high rate of electron-hole pair recombination or band edge emission, and to oxygen vacancies, respectively. However, in the $\mathrm{TiO}_{2}-\mathrm{ZnO}$ nanocomposite, the PL intensity of the TZU75 nanocomposite was considerably reduced with the introduction of $\mathrm{ZnO}$ and the formation of the $\mathrm{TiO}_{2}-\mathrm{ZnO}$ heterojunction which has interfacial charge transport from $\mathrm{TiO}_{2}$ to $\mathrm{ZnO}$, or vice versa. 


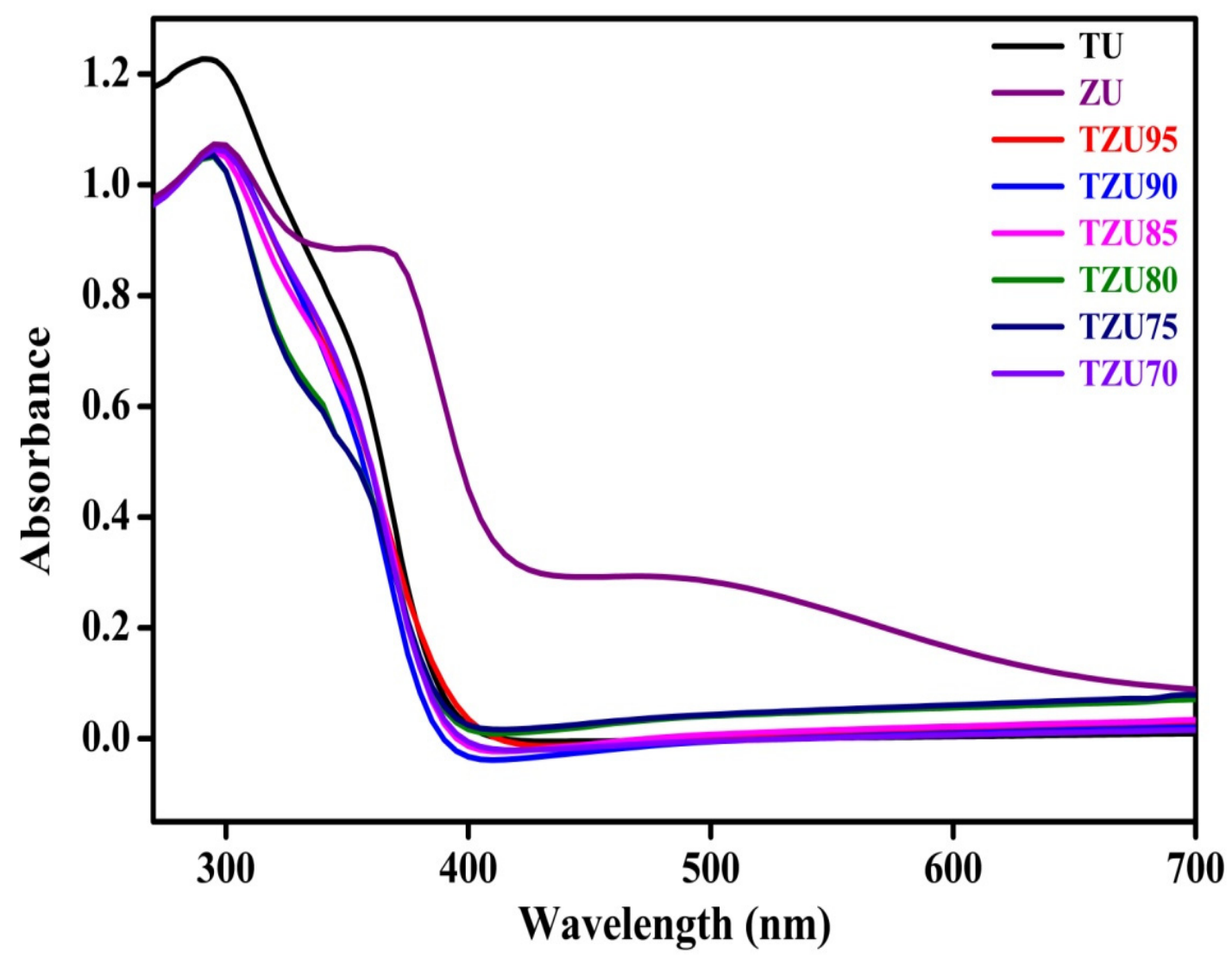

Figure 4. UV-Vis diffuse reflectance spectra of TU, ZU, TZU95, TZU90, TZU85, TZU80, TZU75 and TZU70.

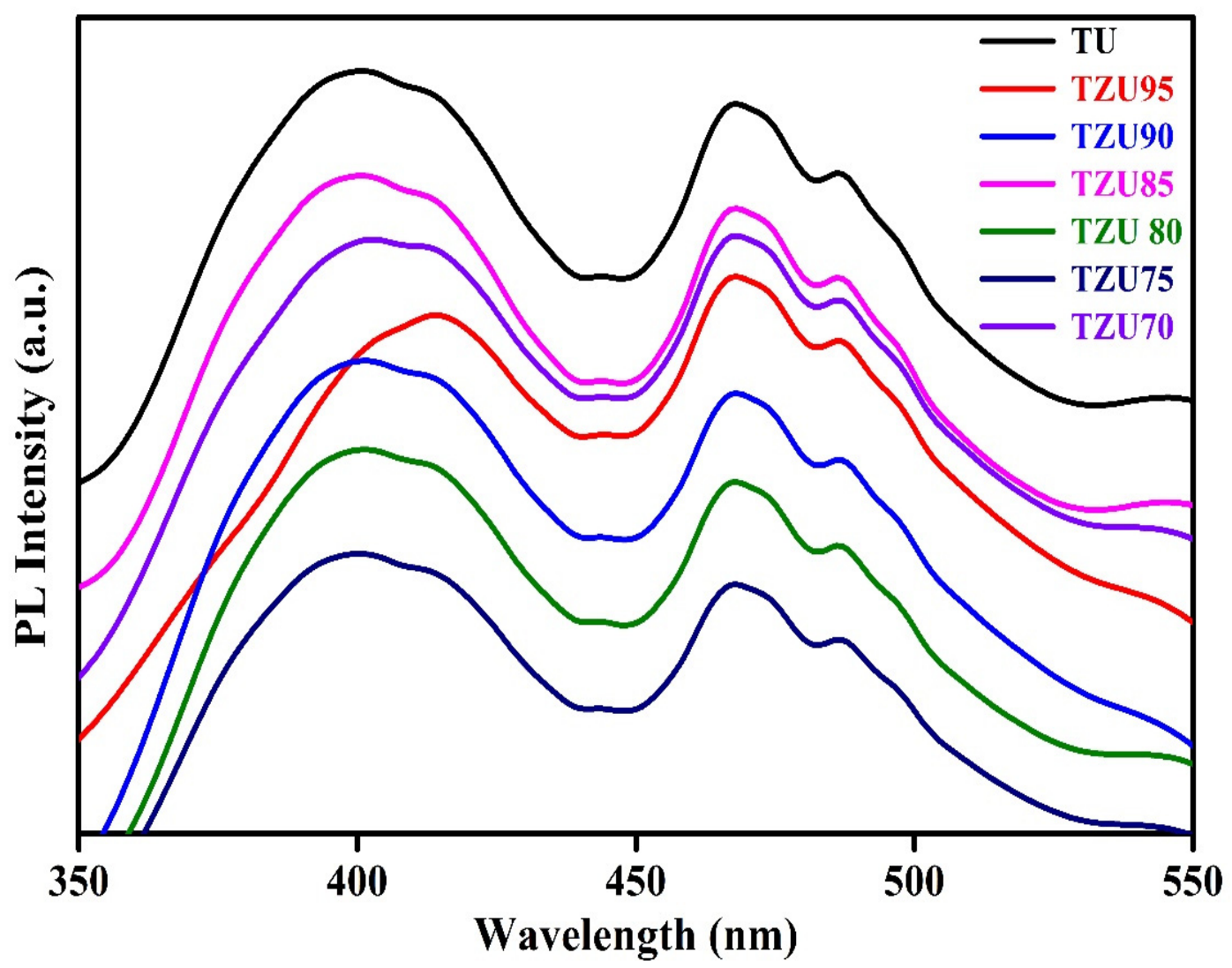

Figure 5. Photoluminescence (PL) spectra of TU, ZU, TZU95, TZU90, TZU85, TZU80, TZU75 and TZU70. 
Due to this, the electron-hole pair recombination rate extensively decreased, and the photocatalytic activity of the $\mathrm{TiO}_{2}-\mathrm{ZnO}$ nanocomposite increased.

\subsection{Photocatalytic Degradation of Methyl Orange Using UV-Visible Light}

The photocatalytic performances of TU, ZU, TZU95, TZU90, TZU85, TZU80, TZU75 and TZU70 were independently evaluated for the degradation of aqueous methyl orange as a pollutant in the presence of a UV-visible light source. The quantity of the aqueous MO solution was calculated from the absorbance $(\lambda \max =464 \mathrm{~nm})$, using UV-Vis spectra. The percent photodegradation $(D \%)$ of $\mathrm{MO}$ under UV light irradiation over the photocatalyst was estimated using the following equation:

$$
D \%=\frac{\left(C_{0}-C\right)}{C_{0}} \times 100 \%
$$

where $C$ and $C_{0}$ are the final and initial concentrations of $\mathrm{MO}$, respectively. The photocatalysis by the as-prepared photocatalysts for MO degradation under UV light illumination is exhibited in Figure 6a-b. The photocatalytic activity of $\mathrm{MO}$ is 79.0, 70, 8, 87, 90, 94, 99.1 and $88 \%$ for TU, ZU, TZU95, TZU90, TZU85, TZU80, TZU75 and TZU70, after being irradiated with UV light for $60 \mathrm{~min}$. It was found that TZU75 showed a much better performance than its counter parts TU (79.03\%) and ZU (70\%) within 60 min, which is ascribed to the constructive heterojunction and interfacial contact between $\mathrm{TiO}_{2}$ and $\mathrm{ZnO}$. It should be noted that the TU and ZU photocatalysts exhibit lower photocatalytic efficiency due to the higher recombination rate of the photogenerated electron-hole pair. Moreover, the photodegradation performance increased with the increasing content of $\mathrm{ZnO}$, due to the formation of the effective heterojunction and the inhibition of electron-hole pair recombination [31]. However, when the $\mathrm{ZnO}$ content was exceeded in TZU70, there was a saturation value and the overall heterostructure was unstable, leading to a decrease in the effective charge transfer process in the heterostructure and a decrease in photocatalytic efficiency [29].
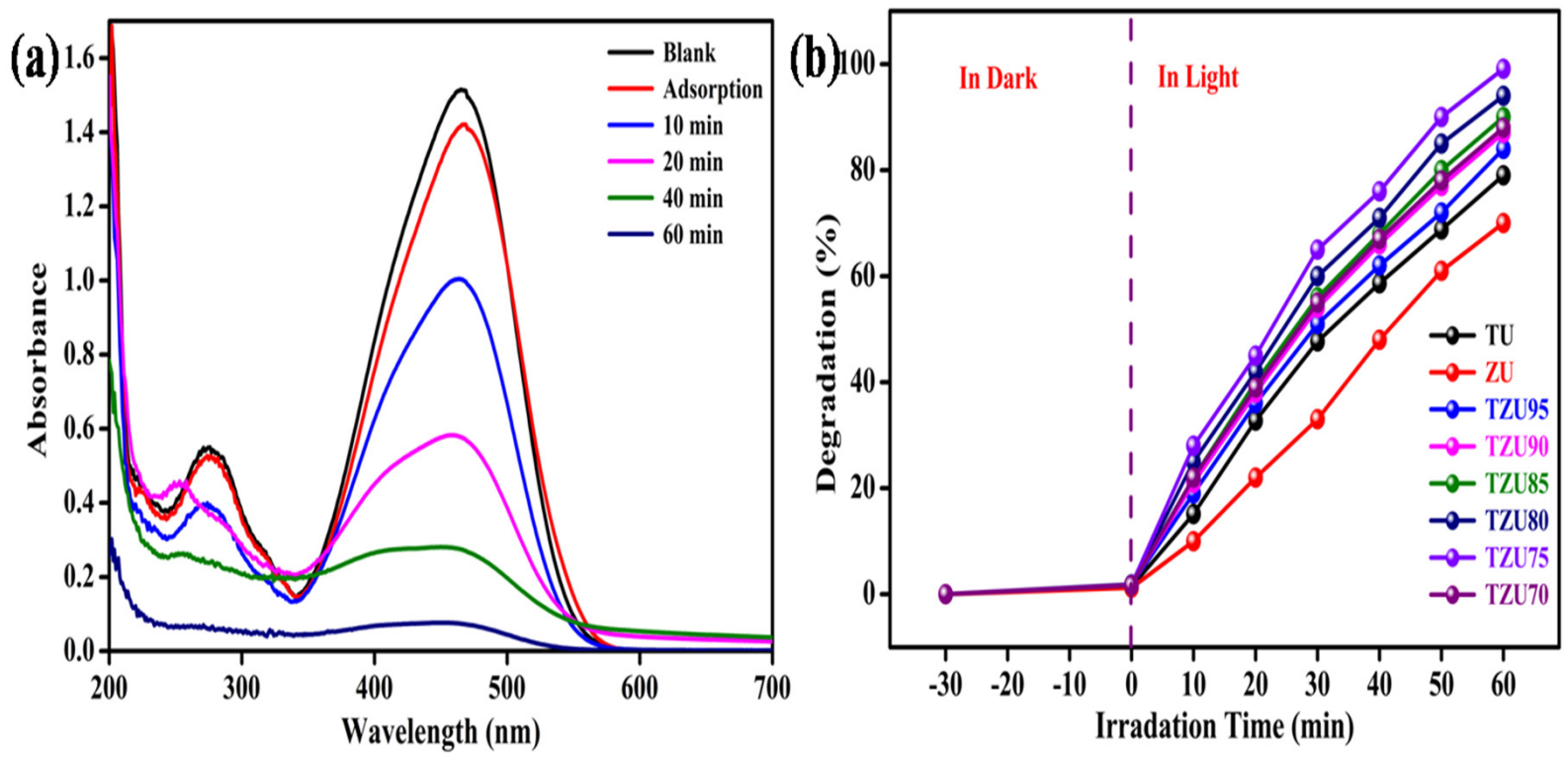

Figure 6. Photocatalytic activity of MO solution over TZU75 under UV light irradiation: (a) absorbance against wavelength; (b) degradation against irradiation time.

The most noteworthy principles of a perfect photocatalyst in a real-world application are its photostability and recyclability. To verify the photostability of the TZU75 nanocomposite, a number of reaction cycles were performed for the degradation of $\mathrm{MO}$ under the same reaction conditions. As shown in Figure 7, after five reaction cycles, the TZU75 
nanocomposite did not display any noteworthy loss of activity. It was observed that the MO photocatalytic activity dropped to $6 \%$ after five consecutive reaction cycles. This result indicates that the TZU75 nanocomposite shows good photostability and recyclability.

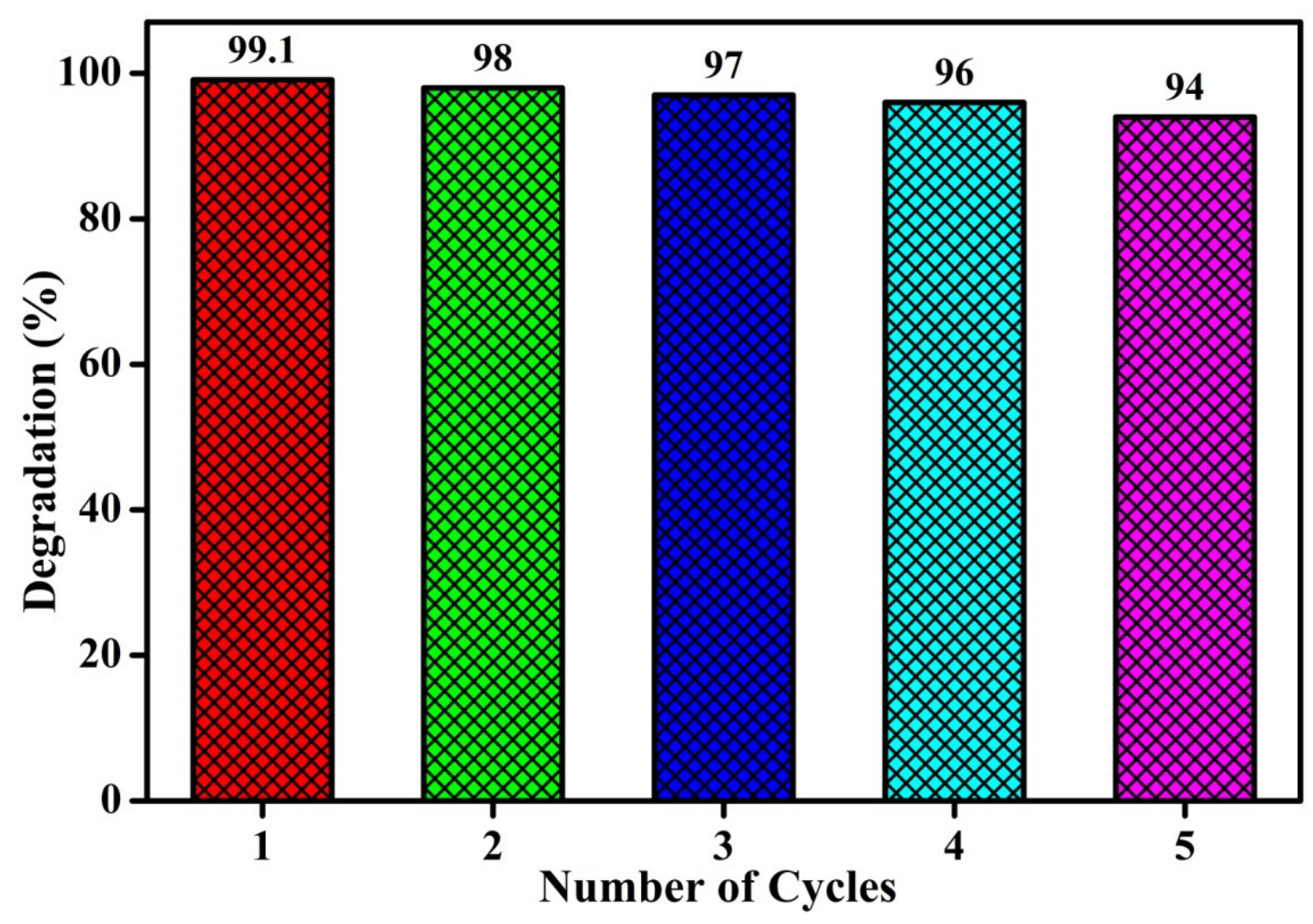

Figure 7. Reusability of TZU75 for MO degradation under UV light irradiation.

On the basis of the above result, the comprehensive plausible mechanism for the photodegradation of $\mathrm{MO}$ dye over the $\mathrm{TiO}_{2}-\mathrm{ZnO}$ nanocomposite is delineated in Scheme 1 . As per the process of the photodegradation of the dye, the photocatalytic activity of the $\mathrm{TiO}_{2}$ $\mathrm{ZnO}$ nanocomposite correlated to the formation of a suitable type II heterojunction between the interface of $\mathrm{ZnO}$ and $\mathrm{TiO}_{2}$, with band gaps of $3.37 \mathrm{eV}$ and $3.2 \mathrm{eV}$, respectively. Under UV-visible light illumination, both $\mathrm{ZnO}$ and $\mathrm{TiO}_{2}$ were excited and produced electrons $\left(\mathrm{e}^{-}\right)$in the CB and holes $\left(\mathrm{h}^{+}\right)$in the VB. More significantly, due to the establishment of the heterojunction between $\mathrm{ZnO}$ and $\mathrm{TiO}_{2}$, the $\mathrm{CB}$ level of $\mathrm{ZnO}$ is lower than the $\mathrm{CB}$ level of $\mathrm{TiO}_{2}$. Photogenerated $\mathrm{e}-$ in the $\mathrm{CB}$ of $\mathrm{TiO}_{2}$ have affinity to transfer into the $\mathrm{CB}$ of $\mathrm{ZnO}$ through the interface; conversely, photogenerated $h^{+}$in the $\mathrm{VB}$ of $\mathrm{TiO}_{2}$ could travel into the $\mathrm{VB}$ of $\mathrm{ZnO}$ [32]. This route could efficiently enhance the lifespan and separation ability of the photoinduced electron-hole pair. Consequently, the photoinduced and separated $\mathrm{e}^{-}$in the $\mathrm{VB}$ of $\mathrm{TiO}_{2}$ capture the surface-adsorbed molecular oxygen to form superoxide radicals $\left(\bullet \mathrm{O}_{2}{ }^{-}\right)$, whereas the $\mathrm{h}^{+}$migrate into the $\mathrm{VB}$ of $\mathrm{ZnO}$ to oxidize $\mathrm{H}_{2} \mathrm{O}$ and to generate hydroxyl radicals $(\bullet \mathrm{OH})$. Finally, both $\bullet \mathrm{O}_{2}{ }^{-}$and $\bullet \mathrm{OH}$ radicals act as strong oxidizing agents to oxidize $\mathrm{MO}$ into carbon dioxide and water molecules. 


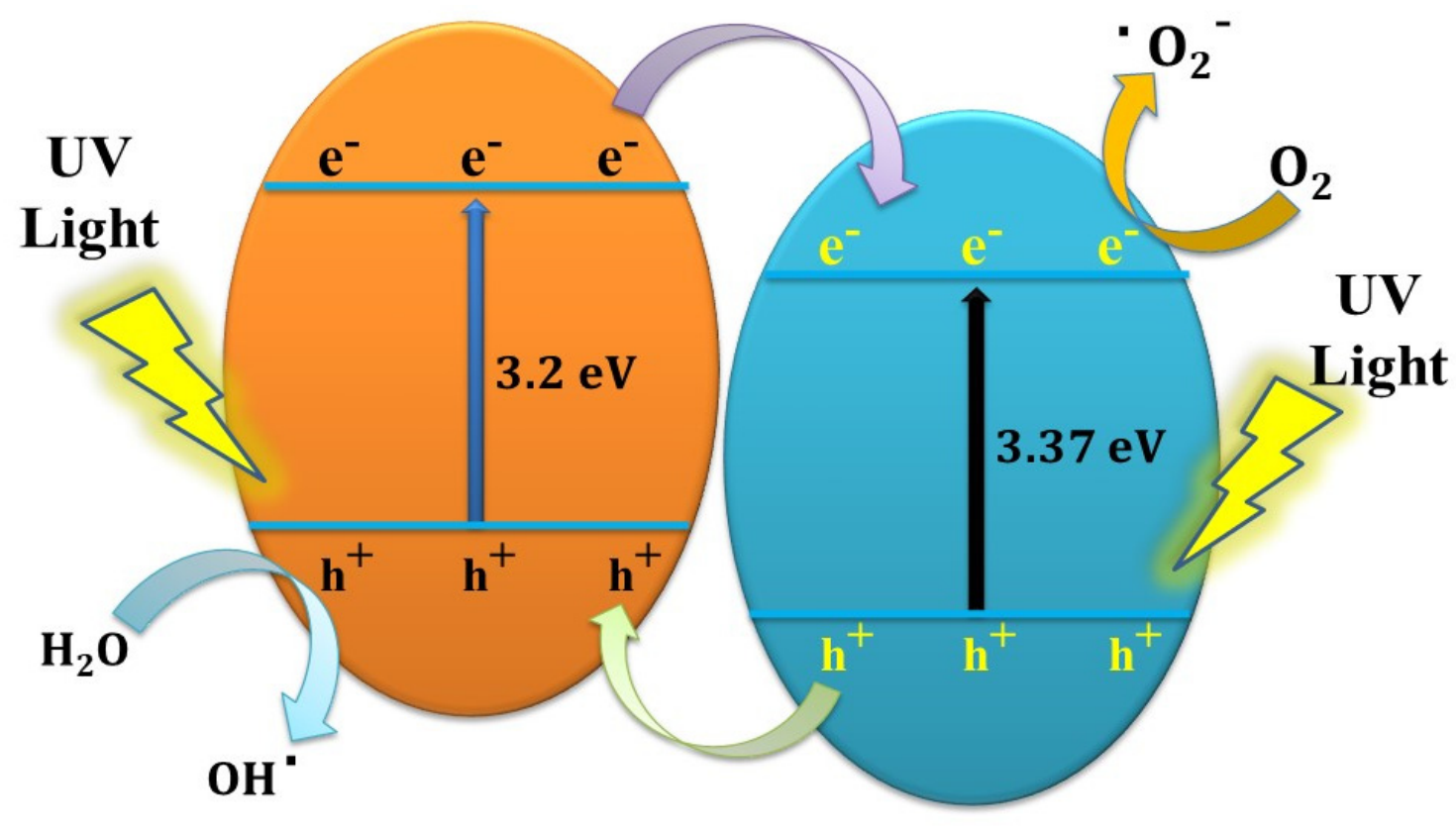

$\mathrm{TiO}_{2}$

ZnO

Scheme 1. Plausible mechanism for the photocatalytic degradation of MO over TZU75 under UV light irradiation.

\section{Conclusions}

In summary, we rationally developed a simple, inexpensive and novel technique for the synthesis of $\mathrm{TiO}_{2}-\mathrm{ZnO}$ nanocomposites, using a thermal decomposition method. The as-synthesized $\mathrm{TiO}_{2}-\mathrm{ZnO}$ nanocomposite was employed for the photodegradation of methyl orange (MO) in the presence of UV-visible light illumination. The degradation study revealed that the $\mathrm{TiO}_{2}-\mathrm{ZnO}$ nanocomposite showed superior photocatalytic activity to pure $\mathrm{TiO}_{2}$ and $\mathrm{ZnO}$. More importantly, the photocatalytic activity of the $\mathrm{TiO}_{2}-\mathrm{ZnO}$ nanocomposite did not exhibit any noticeable decrease and remained stable even after five recycles. The remarkable photocatalytic activity can be ascribed to enhanced charge separation at the interface and to the formation of a heterojunction between $\mathrm{TiO}_{2}$ and $\mathrm{ZnO}$. It is hoped that our unique approach for the synthesis of mixed metal oxide heterostructure nanocomposites may open up a new opportunity for wastewater treatment.

Author Contributions: Writing-original draft and methodology, S.M.D.; writing-review and editing, and validation, S.S.A.; data curation and formal analysis, S.B.B.; funding acquisition and visualization, S.F.S.; project administration and data interpretation, A.M.T.; validation and resources, N.T.N.T.; formal analysis and data collection, C.-D.K.; supervision and investigation, S.M.K.; conceptualization and writing-review and editing, M.S.T.; supervision and project administration, S.R.B. All authors have read and agreed to the published version of the manuscript.

Funding: This research work was funded by the Researchers Supporting Project (number RSP2021/370), King Saud University, Riyadh, Saudi Arabia.

Institutional Review Board Statement: Not Applicable.

Informed Consent Statement: Not Applicable.

Data Availability Statement: Not Applicable.

Acknowledgments: The authors are thankful to the Researchers Supporting Project (number RSP2021/370), King Saud University, Riyadh, Saudi Arabia.

Conflicts of Interest: The authors declare that they have no known competing financial interests or personal relationships that could appear to influence the work reported in this paper. 


\section{References}

1. Li, Q.; Guo, B.; Yu, J.; Ran, J.; Zhang, B.; Yan, H.; Gong, J.R. Highly efficient visible-light-driven photocatalytic hydrogen production of CdS-cluster-decorated graphene nanosheets. J. Am. Chem. Soc. 2011, 133, 10878-10884. [CrossRef]

2. Zhou, M.; Lou, X.W.; Xie, Y. Two-dimensional nanosheets for photoelectrochemical water splitting: Possibilities and opportunities. Sci. Direct 2013, 8, 598-618. [CrossRef]

3. Zhang, A.Y.; Long, L.L.; Liu, C.; Li, W.W.; Yu, H.Q. Chemical recycling of the waste anodic electrolyte from the TiO 2 nanotube preparation process to synthesize facet-controlled $\mathrm{TiO}_{2}$ single crystals as an efficient photocatalyst. Green Chem. 2014, 16, 2745-2753. [CrossRef]

4. Shaikh, A.F.; Arbuj, S.S.; Tamboli, M.S.; Naik, S.D.; Rane, S.B.; Kale, B.B. ZnSe/ZnO Nano-Heterostructures for Enhanced Solar Light Hydrogen Generation. Chem. Sel. 2017, 2, 9174-9180. [CrossRef]

5. Zhang, L.; Wang, W.; Yang, J.; Chen, Z.; Zhan, W.; Zhou, L.; Liu, S. Sonochemical synthesis of nanocrystallite $\mathrm{Bi}_{2} \mathrm{O}_{3}$ as a visible-light-driven photocatalyst. Appl. Catal. A 2006, 308, 105-110. [CrossRef]

6. Li, L.; Chu, Y.; Liu, Y.; Dong, L. Template-Free Synthesis and Photocatalytic Properties of Novel Fe ${ }_{2} \mathrm{O}_{3}$ Hollow Spheres. J. Phys. Chem. C 2007, 111, 2123-2127. [CrossRef]

7. Deshpande, S.P.; Tamboli, M.S.; Arbuj, S.S.; Mulik, U.P.; Amalnerkar, D.P. Synthesis of Nanostructured Ta $2 \mathrm{O}_{5}$ and Its Photocatalytic Performance Study. J. Nanoeng. Nanomanuf. 2014, 4, 215-220. [CrossRef]

8. Smith, Y.R.; Kar, A.; Subramanian, V.R. Investigation of physicochemical parameters that influence photocatalytic degradation of methyl orange over $\mathrm{TiO}_{2}$ nanotubes. Ind. Eng. Chem. Res. 2009, 48, 10268-10276. [CrossRef]

9. Jin, Z.; Duan, W.; Liu, B.; Chen, X.; Yang, F. Fabrication of efficient visible light activated Cu-P25-graphene ternary composite for photocatalytic degradation of methyl blue. J. Appl. Surf. Sci. 2015, 356, 707-718. [CrossRef]

10. Margan, P.; Haghighi, M. Hydrothermal-assisted sol-gel synthesis of Cd-doped $\mathrm{TiO}_{2}$ nanophotocatalyst for removal of acid orange from wastewater. J. Sol-Gel Sci. Technol. 2017, 81, 556-718. [CrossRef]

11. Wang, P.; Yi, X.; Lu, Y.; Yu, H.; Yu, J. In-situ synthesis of amorphous $\mathrm{H}_{2} \mathrm{TiO}_{3}$-modified $\mathrm{TiO}_{2}$ and its improved photocatalytic $\mathrm{H}_{2}$-evolution performance. J. Colloid Interface Sci. 2018, 532, 272-279. [CrossRef]

12. Wang, Y.; Yu, J.G.; Xiao, W.; Li, Q. Microwave-assisted hydrothermal synthesis of graphene based $\mathrm{Au}^{-\mathrm{TiO}} 2$ photocatalysts for efficient visible-light hydrogen production. J. Mater. Chem. A 2014, 2, 3847-3855. [CrossRef]

13. Dong, Z.; Wu, M.H.; Wu, J.Y.; Ma, Y.Y.; Ma, Z.Z. In situ synthesis of $\mathrm{TiO}_{2} / \mathrm{SnO}_{\mathrm{x}}-\mathrm{Au}$ ternary heterostructures effectively promoting visible-light photocatalysis. Dalton Trans. 2015, 44, 11901-11910. [CrossRef]

14. Muzakki, A.; Shabrany, H.; Saleh, R. Synthesis of $\mathrm{ZnO} / \mathrm{CuO}$ and $\mathrm{TiO}_{2} / \mathrm{CuO}$ nanocomposites for light and ultrasound assisted degradation of a textile dye in aqueous solution. AIP Conf. Proc. 2016, 1725, 020051. [CrossRef]

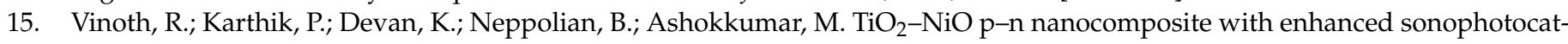
alytic activity under diffused sunlight. Ultrason Sonochem. 2017, 35, 655-663. [CrossRef] [PubMed]

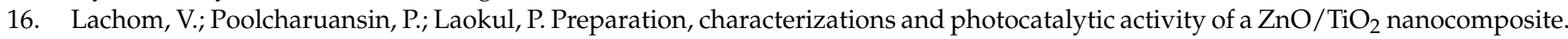
Mater. Res. Express. 2017, 4, 035006. [CrossRef]

17. Arbuj, S.S.; Mulik, U.P.; Amalnerkar, D.P. Synthesis of $\mathrm{Ta}_{2} \mathrm{O}_{5} / \mathrm{TiO}_{2}$ Coupled Semiconductor Oxide Nanocomposites with High Photocatalytic Activity. Nanosci. Nanotechnol. Lett. 2013, 5, 968-973. [CrossRef]

18. Arbuj, S.S.; Hawaldar, R.R.; Mulik, U.P.; Amalnerkar, D.P. Preparation, Characterisation and Photocatalytic Activity of $\mathrm{Nb}_{2} \mathrm{O}_{5} / \mathrm{TiO}_{2}$ Coupled Semiconductor Oxides. J. Nanoeng. Nanomanuf. 2013, 3, 79-83. [CrossRef]

19. Sun, C.; Xu, Q.; Xie, Y.; Ling, Y.; Hou, Y. Designed synthesis of anatase- $\mathrm{TiO}_{2}$ (B) biphase nanowire/ZnO nanoparticle heterojunction for enhanced photocatalysis. J. Mater. Chem. A 2018, 6, 8289-8298. [CrossRef]

20. Wang, J.; Wang, G.; Wei, X.; Liu, G.; Li, J. ZnO nanoparticles implanted in $\mathrm{TiO}_{2}$ macrochannels as an effective direct Z-scheme heterojunction photocatalyst for degradation of RhB. Appl. Surf. Sci. 2018, 456, 666-675. [CrossRef]

21. Liao, M.-H.; Hsu, C.-H.; Chen, D.-H. Preparation and properties of amorphous titania-coated zinc oxide nanoparticles. J. Solid State Chem. 2006, 179, 2020-2026. [CrossRef]

22. Chakma, S.; Moholkar, V.S. Synthesis of bi-metallic oxides nanotubes for fast removal of dye using adsorption and sonocatalysis process. J. Ind. Eng. Chem. 2016, 37, 84-89. [CrossRef]

23. King, D.M.; Liang, X.; Zhou, Y.; Carney, C.S.; Hakim, L.F.; Li, P.; Weimer, A.W. Atomic layer deposition of $\mathrm{TiO}_{2}$ films on particles in a fluidized bed reactor. Powder Technol. 2008, 183, 356-363. [CrossRef]

24. Bahadur, N.M.; Furusawa, T.; Sato, M.; Kurayama, F.; Suzuki, N. Rapid synthesis, characterization and optical properties of TiO 2 coated ZnO nanocomposite particles by a novel microwave irradiation method. Mater. Res. Bull. 2010, 45, 1383-1388. [CrossRef]

25. Deshmukh, S.M.; Tamboli, M.S.; Shaikh, H.; Babar, S.B.; Hiwarale, D.P.; Thate, A.G.; Shaikh, A.F.; Alam, M.A.; Khetre, S.M.; Bamane, S.R. A Facile Urea-Assisted Thermal Decomposition Process of $\mathrm{TiO}_{2}$ Nanoparticles and Their Photocatalytic Activity. Coatings 2021, 11, 165. [CrossRef]

26. He, Y.; Wang, Y.; Zhang, L.; Teng, B.; Fan, M. High-efficiency conversion of $\mathrm{CO}_{2}$ to fuel over ZnO/g-C3N4 photocatalyst. Appl. Catal. B 2015, 168, 1-8. [CrossRef]

27. Houskova, V.; Stengl, V.; Bakardjieva, S.; Murafa, N. Photoactive materials prepared by homogeneous hydrolysis with thioacetamide: Part 2- $\mathrm{TiO}_{2} / \mathrm{ZnO}$ nanocomposites. J. Phys. Chem. Solids 2008, 69, 1623-1631. [CrossRef]

28. Cullity, B.D.; Stock, S.R. Elements of X-ray Diffraction Reading; Addison-Wesley: London, UK, 1978. Available online: https: //www.worldcat.org/title/elements-of-x-ray-diffraction/oclc/3672627 (accessed on 10 September 2021). 
29. Xiao, F.-X. Construction of Highly Ordered $\mathrm{ZnO}-\mathrm{TiO}_{2}$ Nanotube Arrays (ZnO/TNTs) Heterostructure for Photocatalytic Application. ACS Appl. Mater. Interfaces 2012, 4, 7055-7063. [CrossRef] [PubMed]

30. Mane, R.S.; Lee, W.J.; Pathan, H.M.; Han, S.H. Nanocrystalline $\mathrm{TiO}_{2} / \mathrm{ZnO}$ Thin Films: Fabrication and Application to DyeSensitized Solar Cells. J. Phys. Chem. B 2005, 109, 24254-24259. [CrossRef]

31. Hashemi, M.M.; Nikfarjam, A.; Hajghassem, H.; Salehifar, N. Hierarchical Dense Array of ZnO Nanowires Spatially Grown on $\mathrm{ZnO} / \mathrm{TiO}_{2}$ Nanofibers and Their Ultraviolet Activated Gas Sensing Properties. J. Phys. Chem. C 2020, 124, 322-335. [CrossRef]

32. Zha, R.; Nadimicherla, R.; Guo, X. Ultraviolet photocatalytic degradation of methyl orange by nanostructured $\mathrm{TiO}_{2} / \mathrm{ZnO}$ heterojunctions. J. Mater. Chem. A 2015, 3, 6565. [CrossRef] 